\title{
Multi Criterion Decision Making Techniques for Ranking Regional climate models Over Wadi El-Natrun Catchment
}

\author{
Mahmoud A. Refaey ${ }^{1}$ and MHassan ${ }^{2}$, Hany Mostafa ${ }^{3}$, Mostafa Aboelkhear ${ }^{4}$ \\ 1Department of Civil Engineering, Faculty of Engineering at Shoubra, Banha University, Egypt (emahmoud_ali@hotmail.com) \\ 2Department of Civil Engineering, Faculty of Engineering at Shoubra, Banha University, Egypt \\ 3Department of Environmental Studies, Environment and Climate Changes Research Institute, National Water Research Center Building El-Qanater El-Khairiya, \\ P.O. Box 13621, Egypt(hany_moustaf@ hotmail.com) \\ 4Department of Climate change, Environment and Climate Changes Research Institute, National Water Research Center Building El-Qanater El-Khairiya, P.O. \\ Box 13621, (mostafaaboelkhear@gmail.com)
}

Correspondence Author: Mostafa Aboelkhear. Department of Climate change, Environment and Climate Changes Research Institute, National Water Research Center Building El-Qanater El-Khairiya, P.O. Box 13621,

E-mail: (mostafaaboelkhear@gmail.com)

Received date: 18 March 2019, Accepted date: 5 May, Online date: 25 May 2019

Copyright: (C) 2019 Mostafa Aboelkhear et al., This is an open-access article distributed under the terms of the Creative Commons Attribution License, which permits unrestricted use, distribution, and reproduction in any medium, provided the original author and source are credited.

\begin{abstract}
A regional climate model (RCM) is a numerical climate prediction model forced by specified lateral and ocean conditions from a general circulation model (GCM). Multicriterion analysis were used to rank and choose the best regional model for the wadi el-natrun Catchment. Sixteen RCMs were assessed for Wadi El-Natrun Catchment with a gridded resolution of $0.5^{\circ} \times 0.5^{\circ}$ for the mean monthly rainfall and mean monthly temperature using five performance indicators. The performance indicators used were the correlation coefficient, normalized root mean square deviation, absolute normalized root mean square deviation, average absolute relative deviation and skill score. The Entropy method was endorsed to acquire weights of these 5 indicators and PROMETHEE-2 (Preference Ranking Organization Method of Enrichment Evaluation). Multi-criterion decision-making techniques were applied as a new approach in Egypt for ranking sixteen Regional climate models over Wadi El-Natrun Catchment. The outranking relation is calculated and the solutions from best to worst are orderly positioned. Results direct that all entire applied methods give the same regional model for the first rank according to rainfall, for temperature, the first three applied methods (Compromise Programming, Cooperative Game Theory, Weighted average technique) give the same first rank model which have the second rank for PROMETHEE-2 method. The research concluded that the best model for the rainfall is not the same best model for temperature. The results indicated that model ICHECEC-EARTH _SMHI-RCA4 (Middle East and North Africa domain) and MPI-M-MPI-ESM-LR_MPI-CSC-REMO2009 (Africa domain) are the best regional climate model for simulating mean monthly rainfall and mean monthly temperature, respectively over Wadi El-Natrun Catchment. Therefore, they are recommended for the further investigation.
\end{abstract}

Keywords: Multi criterion, PROMETHEE-2, performance indicator, RCMs and Wadi El-Natrun Catchment

\section{INTRODUCTION}

A climate system model is an important tool to investigate the appliances for historical, current and projected climate change. The climate system is denoted in a basic procedure in Global Circulation Models (GCMs), with consolidation of models for different elements of the climate system (Xiao-Ge et al. 2013). The uncertainty supplementary with the formulation of GCMs proceed due to a number of variables. These variables include effects of carbon dioxide which are contrarily parameterized in various GCMs, initial and boundary conditions for the given GCMs, GCMs limitation and model structure, unpredictability and future greenhouse (GHG) and gas emissions (Raju et al. 2014).

Perkins et al. 2007 applied Skill Score (SS) approach to evaluate 14 GCMs peculiar to the ability of GCMs to resemble daily rainfall, daily minimum and maximum temperatures for 12 regions of Australia. The assessment was in regard to how properly individual GCMs could arrest the observed probability density functions for each individual variable and each region. They established that the climate models which should be used could be assessed by SS the skill score methodology.

In 2010, a turnover principle, which reveals the proportion of GCMs ranked in the top ' $\mathrm{n}$ ' for 1-time period were used for ranking 17 GCMs for each 20-year period in accordance with the absolute differences between simulated and observed global average 20-year temperatures were ranked (Macadamet al. 2010). The ranked Atmosphere Ocean General Circulation Models 
Citation: Mahmoud A. Refaey, et al., Multi Criterion Decision Making Techniques for Ranking Regional climate models Over Wadi El-Natrun Catchment. Australian Journal of Basic and Applied Sciences, 13(5): 85-96. DOI: 10.22587/ajbas.2019.13.5.9

(AOGCMs) on regional performance for each 20-year period in accordance with the gridbox wise root mean square difference between the set of simulated 20-year temperatures for the gridboxes comprising the region in dispute and the equivalent set of observed 20-year temperatures. They terminated that that particular kind rankings are not significant in assessing the reliability of projected climate changes simulated by AOGCMs.

Fordham, et al. 2011 employed an ensemble of 20 GCMs over Australia by applying the range of skill and convergence metrics for precipitation according to their skill in reproducing 20-year observed patterns of regional and global climates of interest. They demonstrate that model ranking (match of simulate to observed conditions) differs according to the skill metric used, as well as the climate variable and season considered; although the multi-model averaged result tends to outperform single models at a global scale, at the continental scale at least some models can perform better than the multi-model average; and forecasts for the Australian region, which are often based on a single AOGCM (CSIRO-3.0).

Ojhaet al. 2013 applied an ensemble of 17 GCMs and ranked 10 variables by applying the VCS variable convergence score method for the case of India. A higher consistency was indicated for pressure and temperature, and lower consistency for precipitation and related variables across GCMs. The overall results indicated low convergence in atmospheric attributes for the north eastern part of India.

Raju et al.2014 investigated 5 performance indicators (R, NMRSD, ANMRSD, AARD and SS) to rank 11 GCMs for India for precipitation as a given climate variable. They used the Entropy method to determine the weights of the indicators, and an out ranking based Multi Criterion Decision Making (MCDM) method, PROMETHEE-2. They concluded that the resulting ranking patterns may change with the addition of more indicators, more variables, different GCMs and changes in indicator weights.

GCMs are employed to predict the changes in atmospheric variables under the climate change scenarios defined by the Intergovernmental Panel for Climate Change (IPCC). These climate predictions are delineated at a coarse grid (approximately 150-300 km) and are often biased and hence cannot be used directly in hydrological models for climate change impact assessments. Thus, there is a need for downscaling. There are two main downscaling approaches: dynamic and statistical downscaling (Fowler et al. 2007). In dynamic downscaling a Regional climate model (RCM) is set up for a region of interest and nested within a GCM (Christensen et al. 2007). The RCM avails GCM to express time-varying atmospheric boundary conditions enclosing a finite domain. The RCM resolution is regularly computationally limited to a $12-50 \mathrm{~km}$ and it chronicles for the subGCM grid scale compelling by e.g. complex topographical features and land cover heterogeneities in a physically-based way (Sunyer et al. 2012). However, RCMs commonly acquire the biases and other deficiencies of the GCM, and therefore projected statistical downscaling is often required also for RCM projections, thus RCMs were chosen in this study.

The objectives of this study are intelligible as follows: (1) recognizing and electing performance indicators, five performance indicators were recognized and elected such as the Correlation Coefficient (CC), Normalized Root Mean Square Deviation (NRMSD), Absolute Normalized Root Mean Square Deviation (ANRMSD), Aver-age Absolute Relative Deviation (AARD) and Skill Score (SS), for precipitation and mean temperature. (2) Implementing an appropriate approach for ranking of RCMs: exploring the applicability of a MCDM outranking method, i.e. Entropy Method (EM), Compromise Programming (CP), Cooperative Game Theory (CGT), Weighted Average Technique and PROMETHEE-2 Methods. (3) Comparing between different techniques. (4) Choosing the best regional climate model for both rainfall and temperature.

16 RCMs were selected from Cordex data to be ranked. The abbreviations of the selected 16 RCMs and the organizations involved are presented in Table 1 . These $16 \mathrm{RCMs}$ were evaluated for Wadi El-Natrun Catchment $\left(\operatorname{covering} 1\right.$ grid of $\left.0.5^{\circ} \times 0.5^{\circ}\right)$ using the 5 performance indicators described above.

Table 1. Details of RCMs considered and their acronyms.

\begin{tabular}{|l|l|l|l|l|}
\hline $\begin{array}{l}\text { Model } \\
\text { serial }\end{array}$ & Domain & Model & Driving Model & Driving Model institute \\
\hline M 01 & AFRICA & RCA4 & CCCma-CanESM2 & $\begin{array}{l}\text { CCCma (Canadian Centre for } \\
\text { Climate Modelling and Analysis, } \\
\text { Victoria, BC, Canada) }\end{array}$ \\
\hline M 02 & AFRICA & CCLM4-8-17 & $\begin{array}{l}\text { CNRM-CERFACS- } \\
\text { CNRM-CM5 }\end{array}$ & $\begin{array}{l}\text { Météo-France / Centre National de } \\
\text { Recherches Météorologiques }\end{array}$ \\
\hline M 03 & AFRICA & RCA4 & $\begin{array}{l}\text { CNRM-CERFACS- } \\
\text { CNRM-CM5 }\end{array}$ & $\begin{array}{l}\text { Météo-France / Centre National de } \\
\text { Recherches Météorologiques }\end{array}$ \\
\hline M 04 & AFRICA & RCA4 & $\begin{array}{l}\text { CSIRO-QCCCE- } \\
\text { CSIRO-Mk3-6-0 }\end{array}$ & $\begin{array}{l}\text { Commonwealth Scientific and } \\
\text { Industrial Research Organization }\end{array}$ \\
\hline M 05 & MNA* & RCA4 & ICHEC-EC-EARTH & $\begin{array}{l}\text { A European community Earth- } \\
\text { System Model }\end{array}$ \\
\hline M 06 & AFRICA & HIRHAM5 & ICHEC-EC-EARTH & $\begin{array}{l}\text { A European community Earth- } \\
\text { System Model }\end{array}$ \\
\hline M 07 & AFRICA & CCLM4-8-17 & ICHEC-EC-EARTH & $\begin{array}{l}\text { A European community Earth- } \\
\text { System Model }\end{array}$ \\
\hline M 08 & AFRICA & CCLM4-8-17 & $\begin{array}{l}\text { MOHC-HadGEM2- } \\
\text { ES }\end{array}$ & Met Office Hadley Centre \\
\hline M 09 & AFRICA & REMO2009 & ICHEC-EC-EARTH & $\begin{array}{l}\text { A European community Earth- } \\
\text { System Model }\end{array}$ \\
\hline M 10 & AFRICA & RCA4 & ICHEC-EC-EARTH & A European community Earth- \\
\hline
\end{tabular}


Citation: Mahmoud A. Refaey, et al., Multi Criterion Decision Making Techniques for Ranking Regional climate models Over Wadi El-Natrun Catchment. Australian Journal of Basic and Applied Sciences, 13(5): 85-96. DOI: 10.22587/ajbas.2019.13.5.9

\begin{tabular}{|l|l|l|l|l|}
\hline M 11 & AFRICA & CCLM4-8-17 & $\begin{array}{l}\text { MPI-M-MPI-ESM- } \\
\text { LR }\end{array}$ & $\begin{array}{l}\text { Hystem Model } \\
\text { Climate Service Center, Max Planck } \\
\text { Institute for Meteorology }\end{array}$ \\
\hline M 12 & AFRICA & REMO2009 & $\begin{array}{l}\text { MPI-M-MPI-ESM- } \\
\text { LR }\end{array}$ & $\begin{array}{l}\text { Helmholtz-Zentrum Geesthacht, } \\
\text { Climate Service Center, Max Planck } \\
\text { Institute for Meteorology }\end{array}$ \\
\hline M 13 & AFRICA & RCA4 & $\begin{array}{l}\text { MPI-M-MPI-ESM- } \\
\text { LR }\end{array}$ & $\begin{array}{l}\text { Helmholtz-Zentrum Geesthacht, } \\
\text { Climate Service Center, Max Planck } \\
\text { Institute for Meteorology }\end{array}$ \\
\hline M 14 & AFRICA & CRCM5 & $\begin{array}{l}\text { MPI-M-MPI-ESM- } \\
\text { LR }\end{array}$ & $\begin{array}{l}\text { Helmholtz-Zentrum Geesthacht, } \\
\text { Climate Service Center, Max Planck } \\
\text { Institute for Meteorology }\end{array}$ \\
\hline M 15 & AFRICA & REMO2009 & $\begin{array}{l}\text { NOAA-GFDL- } \\
\text { GFDL-ESM2G }\end{array}$ & $\begin{array}{l}\text { Geophysical Fluid Dynamics } \\
\text { Laboratory }\end{array}$ \\
\hline M 16 & AFRICA & RCA4 & $\begin{array}{l}\text { NOAA-GFDL- } \\
\text { GFDL-ESM2M }\end{array}$ & $\begin{array}{l}\text { Geophysical Fluid Dynamics } \\
\text { Laboratory }\end{array}$ \\
\hline
\end{tabular}

\section{Study Area}

Wadi El-Natrun is a narrow depression located in the west of the Nile Delta, approximately $110 \mathrm{~km}$ northwest of Cairo between longitudes $29^{\circ} 80^{\prime} 00^{\prime \prime}$ and $31^{\circ} 00^{\prime} 00^{\prime \prime} \mathrm{E}$ and latitudes $30^{\circ} 00^{\prime} 00^{\prime \prime}$ and $30^{\circ} 50^{\prime} 00^{\prime \prime} \mathrm{N}$. The total area of the study area around Wadi El-Natrun is roughly $1123 \mathrm{~km}^{2}$ as shown in Figure (1), extending in a NW-SE direction. (Mogith et al. 2013). The topography of study area has an elevation difference of $180 \mathrm{~m}$ between its highest point above the sea level and lowest point blew the sea level. The elevation attains its highest altitude of $160 \mathrm{~m}$ above the sea level around the depression of Wadi El-Natrun and drops to range between $-23 \mathrm{~m}$ and $-15 \mathrm{~m}$ at the center of the depression of Wadi El-Natrun.

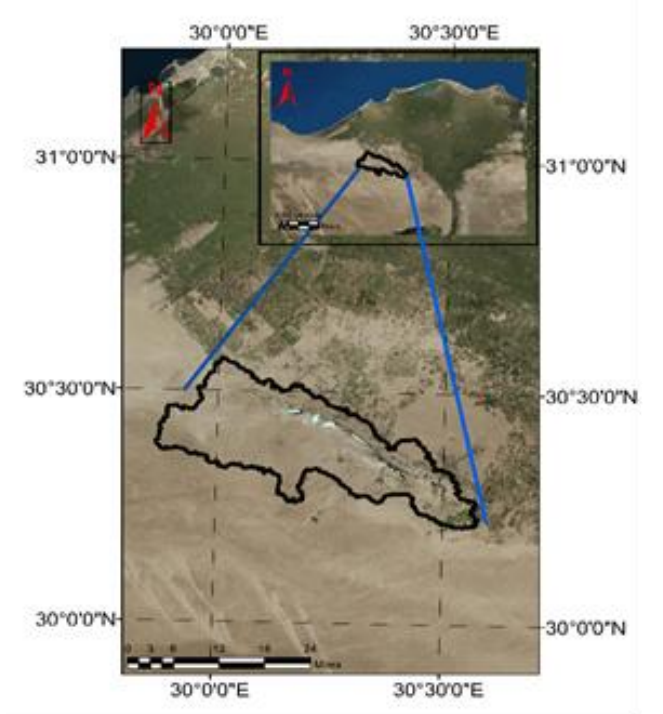

Figure 1. Location of Wadi El-Natrun Catchment

\section{Metadata}

\section{METHODOLOGY}

In this study, simulations of sixteen RCMs from Coordinated Regional Climate Downscaling Experiment (CORDEX) are extracted. RCMs are selected founded on their data availability over the study region (Table 1). Two variables are included: Monthly mean rainfall and monthly mean temperature for historical (1979-2005) from these RCMs. CORDEX project is one of the components endorsed by the World Climate Research Program (WCRP) and was established in 2013 to assess and match RCMs (Giorgi et al.2009).CORDEX provides an internationally coordinated framework to improve regional climate scenarios for many regional domains and provide new statistical methods for downscaling and analysis (Jacob et al.2012 and Nikulin et al.2012).In this context, CORDEX desires to improve the robustness of climate projections at regional scales and at high spatial and temporal resolution in order to enable the AFRICAN society to better adapt to unavoidable climate change and to design more efficient mitigation strategies. In addition, to facilitate the usage of the ensemble of simulations by the Vulnerability, Impact, Adaptation and Climate Services (VIACS) community and other potential users (Bessembinder et al.2015).

As a portion of the universal CORDEX framework, the MENA-CORDEX initiative affords regional climate projections for Middle East and North Africa (MENA) with a grid resolution of $0.44^{\circ}$ x $0.44^{\circ}$ (AFR-44, MNA-44). Moreover, the desired period between 1979- 2005 were extracted from the Earth System Grid Federation websites (https://esgf-data.dkrz.de/search/cordex-dkrz). 
Then the simulated monthly climate dataset was analyzed for ranking the 16 RCMs. This simulated dataset is compared to the observed-historical monthly dataset, extracted by Climatic Research Unit (CRU). The resolution of the gridded dataset is to $0.5^{\circ} \mathrm{x}$ $0.5^{\circ}$.

\section{Performance Indicators}

A performance indicator is driven to verdict the RCMs feature and how well it resembles the Cordex observed data. Five performance indicators, namely (correlation coefficient, normalized root mean square deviation, absolute normalized root mean square deviation, average absolute relative deviation and skill score) where chosen to assess the RCMs (Raju et al. 2014).

\section{(a) The correlation coefficient (CC):}

Correlation coefficient is implemented to assess the compliance between RCM simulated and observed data. The value of CC is such that $-1<\mathrm{CC}<+1$. A CC value of +1 indicates a perfect positive fit. If there is no linear correlation or a weak linear correlation, $\mathrm{CC}$ is almost closer to zero and is computed.

$$
C C=\frac{\sum_{i=1}^{T}\left(x_{i}-\bar{x}\right)\left(y_{i}-\bar{y}\right)}{(T-1) \sigma_{\mathrm{obs}} \sigma_{\mathrm{sim}}}
$$

Where, $\bar{x} ; \bar{y}$ are averages of observed and simulated values, whereas $\sigma_{\mathrm{obs}}$ and $\sigma_{\text {sim }}$ are the standard deviations. (Sharifiet al. 2016).

\section{(b) Normalized Root Mean Square Deviation (NRMSD)}

NRMSD is a measure of the difference between the observed values and the model projected. NRMSD can be expressed as:

$$
\mathrm{NRMSD}=\frac{\sqrt{\frac{1}{T}\left(\sum_{i=1}^{T}\left(x_{i}-y_{i}\right)^{2}\right.}}{\bar{x}}
$$

The smaller the value of NMRSD of the estimate, the better the predictive power of the model. An ideal value of 0 is adopted (Chai et al. 2014).

\section{(c) Absolute Normalized Root Mean Square Deviation (ANRMSD)}

ANRMSD is the ratio of the mean of the differences between the observed and the RCM simulated values to the mean of observed values. ANRMSD is expressed as:

$$
\operatorname{ANRMSD}=\left|\frac{\frac{1}{T}\left(\left(\sum_{i=1}^{T}\left(y_{i}-x_{i}\right)\right)\right.}{\bar{x}}\right| \text { (3) }
$$

Similar to NRMSD, smaller values of ANMBD indicate better performance and it is ideal to have a value of zero. (Chai et al. 2014).

\section{(d) Average Absolute Relative Deviation (AARD)}

AARD can be defined as the average of the absolute values of relative errors and is computed as:

$$
\text { AARD }=\frac{1}{T} \sum_{i=1}^{T}\left|\frac{\left(y_{i}-x_{i}\right)}{x_{i}}\right|(4)
$$

Similar to previous performances, the smaller values indicate better performance of the model, and a value of 0 is preferred (Willmottet al.2005).

(e) Skill Score (SS)

SS affords a portion of coincidence between two probability density functions (PDFs), which grants contrast through the entire PDF (Yinet al. 2018). SS is expressed as:

$$
S S=\frac{1}{T} \sum_{i=1}^{n b} \min \left(f_{m} \cdot f_{0}\right)
$$

where:

$n b$ is number of bins used to calculate the PDF for a given region. $f_{m}, f_{0}$ are the frequencies of values in the given bin from the chosen RCM and of the observed values. Skill score varies between zero and one. The higher the score value, the better the RCM performance (Raju et al. 2014). 


\section{Entropy method}

The Entropy method was selected to reveal the indicators weights for every grid relay on the formulated grid wise payoff matrix (Costa et al. 2002). The Entropy Methods can be expressed as:

$$
E n_{j}=-\frac{1}{\ln (T)} \sum_{a=1}^{T} k_{a j} \ln \left(k_{a j}\right)
$$

and

Where:

$$
D d_{j}=1-E n_{j}
$$

$E n_{j}$ total entropy, $k_{a j}$ is the normalize the payoff matrix, a is the index for RCMs; $\mathrm{j}$ is the index for indicators, $(\mathrm{j}=1,2, \ldots, \mathrm{J})$; $\mathrm{T}$ is the total number of RCMs (16 RCMs as shown in Table 1); $D d_{j}$ is the Degree of diversification and is used to determine the information afford by the outcomes of indicator $\mathrm{j}$;

Hence, Normalized weights of indicators are calculated as:

$$
r_{j}=\frac{D d_{j}}{\sum_{j=1}^{J} D d_{j}}
$$

The uncertainty of the criterion vector become high, when the entropy value is higher and vice versa.

\section{Multi Criterion Decision Making Techniques}

India applied the Multi-criterion decision-making (MCDM) techniques for ranking global climate models. These techniques have been not implemented before in Egypt. Therefore, we proposed the MCDM as a new approach in Egypt and we applied the new approach to rank RCMs over Wadi El-Natrun Catchment for the first time. All (MCDM) used in our study depend on the Weight of indicators for SS, CC, NRMSD, ANRMSD, and AARD (Raju et al. 2014).

(a) Compromise Programming (CP):

$\mathrm{CP}$ is employed to explore multi objective problems related to floods and disaster (Weiet al.2015) (Srinivasa Raju et al. 2016) . It is recognized on distance measure $L_{p}$ metric. The general formulation of a $\mathrm{CP}$ approach is expressed as follows:

$$
L_{p a}=\left[\sum_{j=1}^{J} r_{j}^{p}\left|k_{j}^{*}-k_{j}(a)\right|^{p}\right]^{\frac{1}{p}}
$$

Where;

$\mathrm{j}$ means statistical index; $r_{j}=$ Weight assigned to the indicator $\mathrm{j} ; \mathrm{p}$ is the parameter $(1,2, \ldots \infty) ; k_{j}^{*}$ is the normalized value of index $\mathrm{j}$ being gridded climate variable product; $k_{j}(a)$ is the normalized ideal value of index $\mathrm{j}$ (Value of indicator $\mathrm{j}$ for $\mathrm{RCM}$ ). The $\mathrm{p}$ value of 1 is used for measuring linear and 2 for squared Euclidean distant. The lower $L_{p a}$ value, the better the RCM performance.

\section{(b) Cooperative Game Theory (CGT).}

Parrachinoet al. 2006 stated that CGT has a lot to offer for normative analyses and can be applied on distance measure. CGT can be are calculated as:

$$
D_{a}=\prod_{j=1}^{J}\left|k_{j}(a)-k_{j}^{* *}\right|^{r_{j}}
$$

$k_{j}(a)$ is the value of indicator $\mathrm{j}$ for RCM a; $k_{j}^{* *}$ is Anti-ideal value for each indicator $\mathrm{j}$ among available RCMs; $r_{j}$ the weight assigned to the indicator. The Higher $D_{a}$ value, the better the RCM performance.

(c) Weighted Average Technique, it is utility-related technique.

$$
V_{a}=\left[\sum_{j=1}^{J} r_{j} k_{j}\right]
$$

Where:

$k_{j}=$ Value of indicator $\mathrm{j}$ for RCM a; $r_{j}=$ Weight assigned to the indicator $\mathrm{j}$. weighted average values for other RCMs are computed. Best RCM is the one with maximum weighed average value $V_{a}$ (Raju et al.2018). 
(d) Preference ranking organization method for enrichment evaluation (PROMETHEE-2)

PROMETHEE-2 is considered one of the Multi Criterion Decision Making (MCDM) method of outranking nature (Behzadian et al. 2010 and Brans et al.2016). It is signed to rank the RCMs. The overall characteristic of PROMETHEE is that all alternatives are associated in a pair-wise manner, separately for each criterion.

Let $e_{j}$ (a) be the score of climate adaptation option (a) under criterion $j$. Then, the preference score of two alternatives (a) and (b) is calculated using the preference function $\operatorname{Pr}_{j}(a . b), \mathrm{i} \neq \mathrm{j}$ :

$$
\operatorname{Pr}_{j}(a . b)=\left[\begin{array}{lll}
0 & \text { if } & e_{j}(a)-e_{j}(a) \leq 0 \\
1 & \text { if } & e_{j}(a)-e_{j}(a)>0
\end{array}\right]
$$

The multi-criteria preference degree for alternative (a) against alternative (b) is calculated as the weighted sum of the pairwise preferences over the two alternatives for all criteria.

$$
\pi(a . b)=\frac{\sum_{j=1}^{J} r_{j} \operatorname{Pr}_{j}(a . b)}{\sum_{j=1}^{J} r_{j}}
$$

The PROMETHEE-2 outranking method offers two penchant flows. The first, $\phi^{+}(a)$, imitates how powerfully an alternative (a) rules all other alternatives and the second, $\phi^{-}(a)$, reveals how strongly (a) is ruled by all alternatives.(Nigussieet al. 2018)

$$
\begin{gathered}
\phi^{+}(a)=\frac{\sum_{A} \pi(a . b)}{(T-1)} \\
\phi^{-}(a)=\frac{\sum_{A} \pi(b . a)}{(T-1)} \\
\text { Net } \phi=\phi^{+}(a)+\phi^{-}(a)
\end{gathered}
$$

where $r_{j}$ is the weight assigned to the indicator $\mathrm{j} ; \phi^{+}(a)$ is the outranking index of a in the RCMS setT; $\phi^{-}(a)$ is the outranked index of a in the RCMS set T; Net $\phi$ is the net ranking of a in the RCM set $T$, and $\mathrm{J}$ is the number of indicators. The RCM having the highest $N e t \phi$ value is considered to be the most suitable RCM (Raju et al. 2014).

\section{Results and Discussion}

(a)Analysis of indicators

Table 2 and Table 3 demonstrate the values obtained for the 5 indicators (CC, NMRSD, ANMRSD, AARD and SS), (Equations. 1-5) for the selected 16 RCMs for rainfall and Temperature, respectively. Zero or minimum or error is appropriate in the incident of NMRSD, ANMRSD and AARD, however an ultimate value of 1 is appropriate for CC and SS. An inappropriate negative sign is employed before the values associated to NMRSD, ANMRSD and AARD to make them maximization type and to be compatible with CC and SS.

Table 2. Performance indicators obtained for the 16 chosen Regional climate models (RCMs) Monthly Mean Rainfall data for the Wadi El-Natrun Catchment, Egypt.

\begin{tabular}{|l|l|l|l|l|l|}
\hline RCMs & CC & NRMSD & ANRMSD & AARD & SS \\
\hline M 01 & 0.37 & 1.38 & 0.88 & 0.69 & 0.42 \\
\hline M 02 & -0.01 & 1.31 & 0.67 & 1.55 & 0.58 \\
\hline M 03 & 0.17 & 1.18 & 0.49 & 1.28 & 0.67 \\
\hline M 04 & 0.30 & 1.23 & 0.68 & 0.53 & 0.58 \\
\hline M 05 & 0.65 & 0.69 & 0.31 & 0.37 & 0.75 \\
\hline M 06 & 0.44 & 1.03 & 0.48 & 0.61 & 0.75 \\
\hline M 07 & 0.54 & 1.20 & 0.71 & 0.46 & 0.50 \\
\hline M 08 & 0.22 & 1.08 & 0.36 & 0.97 & 0.67 \\
\hline M 09 & 0.56 & 1.19 & 0.72 & 0.63 & 0.50 \\
\hline M 10 & 0.29 & 1.22 & 0.66 & 0.65 & 0.58 \\
\hline M 11 & 0.44 & 1.19 & 0.68 & 0.43 & 0.58 \\
\hline M 12 & 0.39 & 1.22 & 0.70 & 0.43 & 0.58 \\
\hline M 13 & 0.16 & 1.21 & 0.54 & 0.51 & 0.67 \\
\hline M 14 & 0.16 & 1.21 & 0.54 & 0.51 & 0.67 \\
\hline M 15 & 0.56 & 1.08 & 0.61 & 0.72 & 0.58 \\
\hline M 16 & 0.10 & 1.22 & 0.46 & 1.77 & 0.67 \\
\hline$E n_{j}$ (Eq.6) & 4.69 & 1.00 & 0.99 & 0.95 & 1.00 \\
\hline$D d_{j}$ (Eq.7) & -3.69 & 0.00 & 0.01 & 0.05 & 0.00 \\
\hline$r_{j}$ (Eq.8) & 1.02 & 0.00 & 0.00 & -0.01 & 0.00 \\
\hline
\end{tabular}


Table 3. Performance indicators obtained for the 16 chosen Regional climate models (RCMs)Monthly Mean Temperature data for the Wadi El-Natrun Catchment, Egypt

\begin{tabular}{|l|l|l|l|l|l|}
\hline RCMs & CC & NRMSD & ANRMSD & AARD & SS \\
\hline M 01 & 0.97 & 0.08 & 0.01 & 0.08 & 0.25 \\
\hline M 02 & 0.98 & 0.11 & 0.04 & 0.10 & 0.42 \\
\hline M 03 & 0.97 & 0.09 & 0.04 & 0.09 & 0.33 \\
\hline M 04 & 0.98 & 0.06 & 0.01 & 0.06 & 0.33 \\
\hline M 05 & 0.90 & 0.13 & 0.11 & 0.12 & 0.50 \\
\hline M 06 & 0.98 & 0.06 & 0.04 & 0.05 & 0.50 \\
\hline M 07 & 0.96 & 0.10 & 0.07 & 0.10 & 0.25 \\
\hline M 08 & 0.93 & 0.10 & 0.10 & 0.11 & 0.42 \\
\hline M 09 & 0.95 & 0.09 & 0.08 & 0.09 & 0.33 \\
\hline M 10 & 0.95 & 0.09 & 0.06 & 0.09 & 0.42 \\
\hline M 11 & 0.99 & 0.07 & 0.01 & 0.07 & 0.42 \\
\hline M 12 & 0.99 & 0.03 & 0.01 & 0.03 & 0.58 \\
\hline M 13 & 0.98 & 0.05 & 0.00 & 0.04 & 0.42 \\
\hline M 14 & 0.98 & 0.05 & 0.00 & 0.04 & 0.42 \\
\hline M 15 & 0.96 & 0.11 & 0.08 & 0.11 & 0.50 \\
\hline M 16 & 0.96 & 0.10 & 0.07 & 0.10 & 0.50 \\
\hline$E n_{j}$ (Eq.6) & 14.53 & 0.98 & 0.88 & 0.98 & 0.99 \\
\hline$D d_{j}$ (Eq.7) & -13.5 & 0.02 & 0.12 & 0.02 & 0.01 \\
\hline$r_{j}$ (Eq.8) & 1.01 & 0.00 & -0.01 & 0.00 & 0.00 \\
\hline
\end{tabular}

On Table 2 and table 3, the results highlighted in different color according to their rank

\begin{tabular}{|l|l|}
\hline Color & Key \\
\hline & Max \\
\hline & Min \\
\hline
\end{tabular}

As shown in Table 2 for rainfall, CC (Eq. 1), (M05) was correlated well with the observed data with a value of 0.65 , whereas a minimum CC was desired for (M02) with a value of -0.01. This aspect is extended spatially for 1 grid point (50X50 km) covering Wadi El-Natrun. Similar trends were detected for SS (Eq. 5). In this case, (M05 and M06) shows $75 \%$ similarity with the observed PDFs, however (M01) shows only $42 \%$ similarity. While, NRMSD indicator (Eq. 2) displays that (M01) is the desired RCM, with an NRMSD value of 1.38, whereas (M05) is the least preferred (NRMSD = 0.69). For ANMRSD (Eq. 3) as well, (M01) is the preferred RCM (0.88) whereas (M05) is the least preferred (0.31). For AARD (Eq. 4), (M16) and (M05) are the most and least desired RCMs, respectively.

Table 3 shows that in the case of CC (Eq. 1), (M12) was correlated well with the observed data with a value of 0.99, whereas a minimum CC was observed for (M05) with a value of 0.90. This aspect is extended spatially covering Wadi El-Natrun. Similar trends were observed for SS (Eq. 5). In this case, (M12) shows $58 \%$ similarity with the observed PDFs, whereas (M07) shows only $25 \%$ similarity. However, NRMSD indicator (Eq. 2), (M05) is the preferred RCM, with an NRMSD value of 0.13 , whereas (M12) is the least desired (NRMSD =0.03). For ANMRSD (Eq. 3) as well, (M05) is the preferred RCM (0.11) whereas (M13 and M14) is the least favored (0). For AARD (Eq. 4), (M05) and (M12) are the most and least desired RCMs, respectively. The analysis indicates that each indicator reacts contrarily for various RCMs.

In this study, an effort was made to discover all 5 indicators simultaneously to assess their applicability (and their relative contribution) while ranking the RCMs.

\section{(b) Application of Entropy method}

Entire indicator values in Table 2 and Table 3 were normalized using $\frac{f_{j}(i)}{\sum_{i=1}^{N} f_{j}(i)}$ to safeguard that the criterion with a larger variety would not control the criterion with a tinner variety, and to make them harmonious with the desires of the Entropy method ( Raju et al. 2014). Table 2 and Table 3 also promote total entropy $E n_{j}$ (Eq. 6), the degree of diversification $D d_{j}$ (Eq. 7) and the normalized weight $r_{j}$ of each indicator (Eq. 8). Between the 5 indicators, for rainfall CC has the peak value of $102 \%$, which means that its effect on ranking of RCMs is significant. The overall contribution of NRMSD and SS and AARD and ANMRSD is less than $0 \%$. In case of Temperature $\mathrm{CC}$ has the peak value (101\%), which means that its effect on ranking of RCMs is significant. The entire contribution of NRMSD, ANMRSD, AARD and SS is less than $0 \%$. 


\section{(c) Application of Compromise Programming}

$\mathrm{CP}$ is used to measure $L_{p a}$ metric. Appropriate RCM is the one, which have the least $L_{p a}$ metric value (Eq. 9). In the case of rainfall, (M05) has been ranked as first rank with the Lowest $L_{p a}=$ equal to zero and (M02) has the last rank with the highest $L_{p a}=$ 0.678, as shown in Table 4a. For Temperature, as shown in Table 4b, (M12) has been ranked as first rank with the Lowest $L_{p a}=$ 0.0 and (M05) has the last rank with the Highest $L_{p a}=0.098$.

\section{(d) Application of Cooperative Game Theory}

It is recognised on distance measure which far as possible to anti-ideal, so Rank of 1 is the highest $D_{a}$ (Eq. 10) and least rank is the lowest $D_{a}$ value is to be given. As shown in Table 4a, for Rainfall, (M05) has the Rank of 1 with the highest $D_{a}=0.643$ and (M01 and M02) has the least Rank with the lowest $D_{a}=0.0$. As shown in Table 4b, for temperature, (M12) has the Rank of 1 with the highest $D_{a}=0.146$ and (M01 andM07) has the least Rank with the Lowest $D_{a}=0.0$.

\section{(e) Application of Weighted Average Technique}

It be contingent on the weighted average values for other RCMs. Ideal RCMS is the one with supreme weighed average value $V_{a}$ (Eq. 11). (M05) and (M12) with convenience values of 0.598 and 0.49 occupied $1^{\text {st }}$ and $2^{\text {nd }}$ positions respectively, while (M02) with utility values of -0.039 occupied $16^{\text {th }}$ position for the Rainfall, as shown in Table 4a. However, (M12) and (M06) with convenience values of 0.173 and 0.129 occupied $1^{\text {st }}$ and $2^{\text {nd }}$ positions respectively, whereas, (M02) with convenience values of 0.018 occupied $16^{\text {th }}$ position for the temperature, as shown in Table $4 \mathrm{~b}$.

\section{f) Application of PROMETHEE-2}

This method is considered the easiest approach for resolving a multicriterion problem. By applying Eq. 12 to Eq.16, theNet $\phi$ value can be estimated. The RCMs having the highest Net $\boldsymbol{\phi}$ value is considered the best model. For Rainfall, Table 4a shows that (M05) has the highest Net $\phi$ value of 0.998 and therefore it is considered the best model (Rank 1), followed by (M11) with a Net $\phi$ value of 0.432 . While, (M02) is ranked lowest due to its lowNet $\phi$ value of -0.858 . M05, M11 and M07monopolise the first three locus. In case of temperature (M13) has the peak Net $\phi$ value of 0.902 and therefore is considered the best model (Rank 1), followed by (M12) with a Net $\phi$ value of 0.820. (M05) is ranked lowest due to its low Net $\phi$ value of -0.895 . M13, M12 and M01monopolise the first three locus, as shown in Table 4b.

Results direct that entire ranking methods give the same ranking. For rainfall, Table 4a, displays that (M05) is the best model. According to temperature, Table $4 \mathrm{~b}$ demonstrates that (M12) is considered the best model for three applied methods (Compromise Programming, Cooperative Game Theory, Weighted average technique) and the second best model for PROMETHEE-2 method.

Figure 2 and Figure 3 demonstrate the output results of observed historical data and simulated historical data over Wadi ElNatrun Catchment. As shown in Figure 2 there was a lot of variance between observed and simulated RCMs. Model M05 (ICHEC-EC-EARTH_SMHI-RCA4) (Middle East and North Africa domain) indicates the best curve aligning with historical data (CRU) for simulating mean monthly rainfall. While, Figure 3 demonstrates that the Model M12 (MPI-M-MPI-ESM-LR_MPICSC-REMO2009) (Africa domain) has the best performance for simulating mean monthly temperature due to the best curve fitting. 
Citation: Mahmoud A. Refaey, et al., Multi Criterion Decision Making Techniques for Ranking Regional climate models Over Wadi El-Natrun Catchment. Australian Journal of Basic and Applied Sciences, 13(5): 85-96. DOI: 10.22587/ajbas.2019.13.5.9

Table 4. Ranking of 4 Multi-decision-making methods (Compromise Programming, Cooperative Game Theory, Weighted average technique and PROMETHEE-2) for the 16 chosen Regional climate models (RCMs) (a) Ranking of Mean Monthly Rainfall, (b) Ranking of Mean Monthly Temperature over Wadi El-Natrun Catchment

(a) Ranking of Mean Monthly Rainfall

\begin{tabular}{|c|c|c|c|c|c|c|c|c|}
\hline$R C M$ & $(C P) L_{p a}$ & Rank & $(C G T) D_{a}$ & Rank & (Weighted average technique) $V_{a}$ & Rank & (PROMETHEE-2) Net $\phi$ & rank \\
\hline M 01 & 0.290 & 8 & 0.000 & 15 & 0.293 & 8 & -0.225 & 12 \\
\hline M 02 & 0.678 & 16 & 0.000 & 15 & -0.039 & 16 & -0.858 & 16 \\
\hline M 03 & 0.490 & 12 & 0.188 & 11 & 0.137 & 12 & -0.430 & 14 \\
\hline М 04 & 0.360 & 9 & 0.292 & 8 & 0.246 & 9 & -0.018 & 8 \\
\hline M 05 & 0.000 & 1 & 0.643 & 1 & 0.598 & 1 & 0.998 & 1 \\
\hline M 06 & 0.212 & 5 & 0.445 & 5 & 0.395 & 5 & 0.360 & 4 \\
\hline M 07 & 0.116 & 4 & 0.475 & 4 & 0.460 & 4 & 0.430 & 3 \\
\hline M 08 & 0.440 & 11 & 0.237 & 10 & 0.186 & 11 & -0.274 & 13 \\
\hline M 09 & 0.098 & 3 & 0.491 & 3 & 0.476 & 3 & 0.256 & 7 \\
\hline M 10 & 0.373 & 10 & 0.282 & 9 & 0.235 & 10 & -0.200 & 11 \\
\hline M 11 & 0.216 & 6 & 0.414 & 6 & 0.376 & 6 & 0.432 & 2 \\
\hline M 12 & 0.270 & 7 & 0.367 & 7 & 0.326 & 7 & 0.293 & 5 \\
\hline M 13 & 0.503 & 13 & 0.175 & 12 & 0.125 & 13 & -0.161 & 9 \\
\hline M 14 & 0.503 & 13 & 0.175 & 12 & 0.125 & 13 & -0.161 & 9 \\
\hline M 15 & 0.093 & 2 & 0.523 & 2 & 0.490 & 2 & 0.285 & 6 \\
\hline M 16 & 0.563 & 15 & 0.119 & 14 & 0.071 & 15 & -0.726 & 15 \\
\hline
\end{tabular}

(b)Ranking of Mean Monthly Temperature

\begin{tabular}{|c|c|c|c|c|c|c|c|c|}
\hline $\mathbf{R C M}$ & (CP) $L_{p a}$ & Rank & $\left(\right.$ CGT) $D_{a}$ & Rank & (Weighted average technique) $V_{a}$ & Rank & (PROMETHEE-2) Net $\phi$ & rank \\
\hline М 01 & 0.027 & 9 & 0.000 & 14 & 0.031 & 15 & 0.578 & 3 \\
\hline M 02 & 0.019 & 7 & 0.038 & 13 & 0.065 & 12 & -0.146 & 10 \\
\hline M 03 & 0.020 & 8 & 0.050 & 11 & 0.052 & 14 & -0.135 & 9 \\
\hline M 04 & 0.014 & 4 & 0.072 & 6 & 0.071 & 11 & 0.400 & 6 \\
\hline M 05 & 0.098 & 16 & 0.000 & 14 & 0.080 & 9 & -0.895 & 16 \\
\hline M 06 & 0.015 & 6 & 0.109 & 2 & 0.129 & 2 & 0.334 & 7 \\
\hline M 07 & 0.032 & 10 & 0.000 & 14 & 0.018 & 16 & -0.496 & 13 \\
\hline M 08 & 0.061 & 15 & 0.049 & 12 & 0.071 & 10 & -0.778 & 15 \\
\hline M 09 & 0.041 & 13 & 0.053 & 9 & 0.054 & 13 & -0.443 & 12 \\
\hline M 10 & 0.044 & 14 & 0.066 & 7 & 0.081 & 8 & -0.135 & 8 \\
\hline M 11 & 0.004 & 2 & 0.088 & 5 & 0.096 & 7 & 0.492 & 4 \\
\hline M 12 & 0.000 & 1 & 0.146 & 1 & 0.173 & 1 & 0.820 & 2 \\
\hline M 13 & 0.011 & 3 & 0.103 & 3 & 0.108 & 3 & 0.902 & 1 \\
\hline M 14 & 0.014 & 5 & 0.098 & 4 & 0.104 & 4 & 0.417 & 5 \\
\hline M 15 & 0.036 & 11 & 0.052 & 10 & 0.097 & 6 & -0.645 & 14 \\
\hline M 16 & 0.038 & 12 & 0.061 & 8 & 0.101 & 5 & -0.270 & 11 \\
\hline
\end{tabular}

On this table, the results highlighted in different color according to their rank

\begin{tabular}{|l|l|l|l|l|l|l|l|}
\hline Color & Key & Color & Key & Color & Key & Color & Key \\
\hline & $\mathbf{1}^{\text {st }}$ Rank & & $\mathbf{3}^{\text {rd }}$ Rank & & $\mathbf{2}^{\text {nd }}$ Rank & & $\mathbf{4}^{\text {th }}$ Rank \\
\hline
\end{tabular}


Citation: Mahmoud A. Refaey, et al., Multi Criterion Decision Making Techniques for Ranking Regional climate models Over Wadi El-Natrun Catchment. Australian Journal of Basic and Applied Sciences, 13(5): 85-96. DOI: 10.22587/ajbas.2019.13.5.9

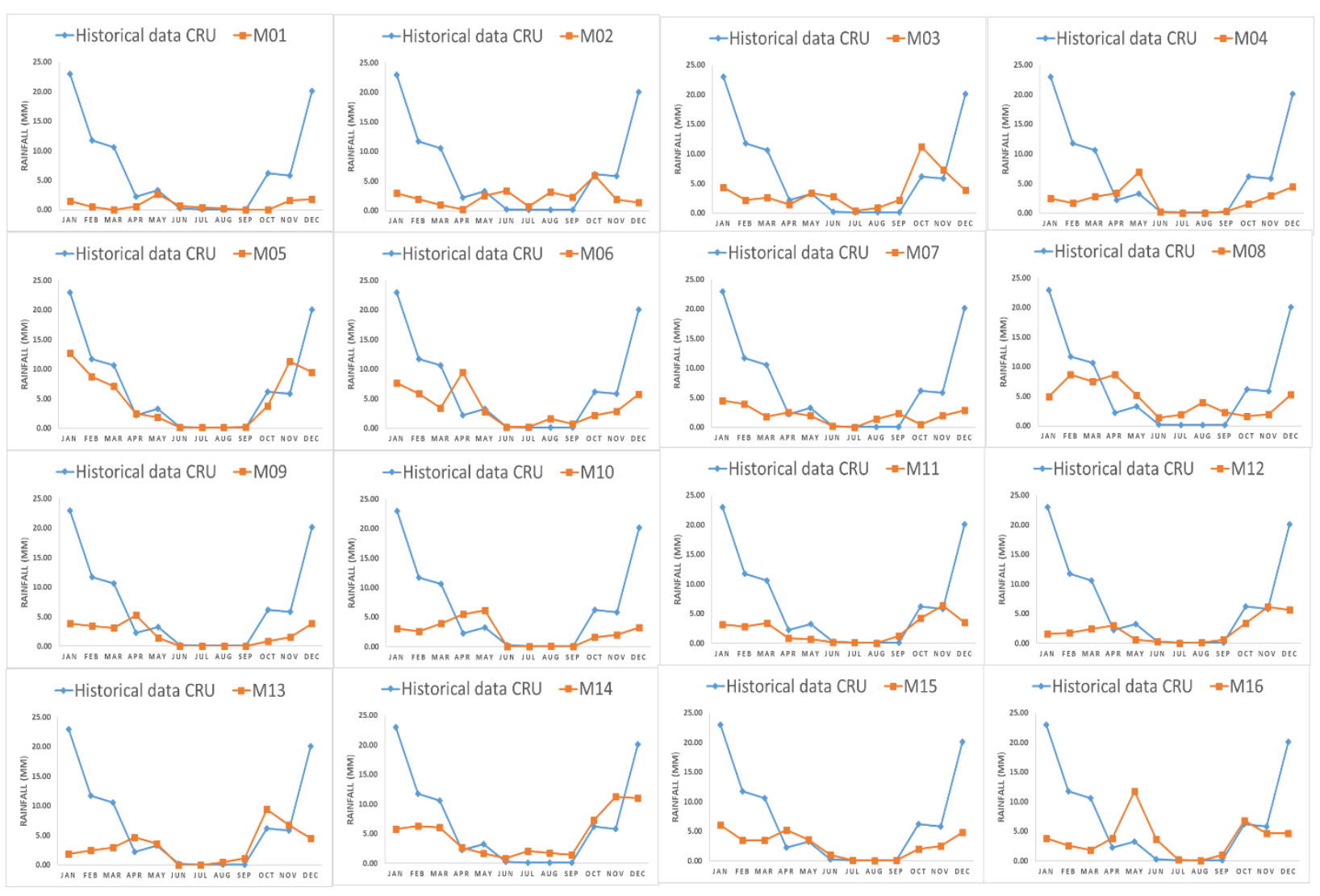

Figure 2. Comparison of Mean Monthly Rainfall of Observed Historical Data (CRU) and Simulated Historical Data RCMS

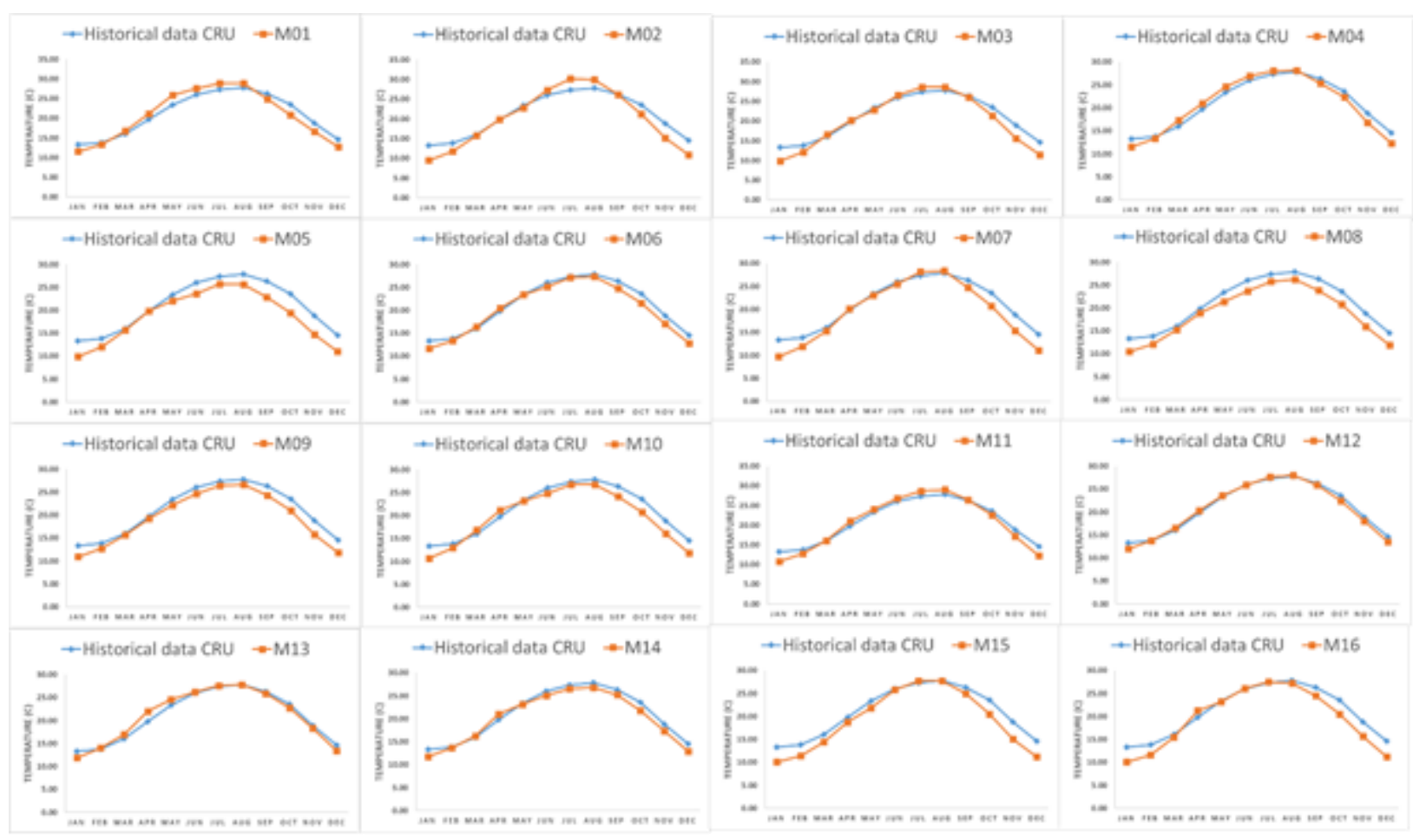

Figure 3. Comparison of Mean Monthly Temperature of Observed Historical Data (CRU) and Simulated Historical Data RCMS 
Citation: Mahmoud A. Refaey, et al., Multi Criterion Decision Making Techniques for Ranking Regional climate models Over Wadi El-Natrun Catchment. Australian Journal of Basic and Applied Sciences, 13(5): 85-96. DOI: 10.22587/ajbas.2019.13.5.9

\section{CONCLUSION}

Five performance indicators (CC, NMRSD, ANMRSD, AARD and SS) were implemented to rank 16 RCMs for Wadi ElNatrun Catchment for climatic variable mean monthly rainfall and mean monthly temperature. A multi criteria decision making method was proposed for Wadi El-Natrun Catchment, as new approach in Egypt with its four ranking methods (Compromise Programming, Cooperative Game Theory, Weighted Average Technique and PROMETHEE-2 Methods). This new approach was found to be more accurate for appraising extreme events. We demonstrate that, the entire methods used for analyzing multi criteria decision making provide the same ranking for rainfall and temperature.

Among the 16 RCMs, the study revealed that, ICHEC-EC-EARTH_SMHI-RCA4 (Middle East and North Africa domain) (M05) and MPI-M-MPI-ESM-LR_MPI-CSC-REMO2009 (Africa domain) (M12) were the best regional climate model for simulating mean monthly rainfall and mean monthly temperature, respectively over Wadi El-Natrun Catchment. Therefore, they are recommended for the further investigation.

\section{ACKNOWLEDGEMENT}

We would like to express our gratitude to the Environment and Climate Changes Research Institute, National Water Research Center, Egypt which kindly provided us with CRU and regional climate models observation data for Wadi El-Natrun. We acknowledge the directors and the technical staff of Environment and Climate Changes Research Institute and department of Civil Engineering, Faculty of Engineering at Shoubra, Banha University for their valuable inputs.

\section{REFERENCES}

Behzadian, M., Kazemzadeh, R.B., Albadvi, A. and Aghdasi, M., 2010. PROMETHEE: A comprehensive literature review on methodologies and applications. European journal of Operational research, 200(1), pp.198-215. DOI:10.1016/j.ejor.2009.01.021

Bessembinder J., Doblas-Reyes FJ, Martins H, Brodeau L., Djurdjevic V., Gallo F., Garret N. Gualdi S., Jacob D., Kotova L., Massonnet F. and Teichmann G.(2015) "Report on European Earth System Modeling for Climate Services". Climate Europe

Brans, J.P. and De Smet, Y., 2016. PROMETHEE methods. In Multiple Criteria Decision Analysis (pp. 187-219). Springer, New York, NY. DOI 10.1007/978-1-4939-3094-4_6

Chai, T. and Draxler, R.R., 2014. Root mean square error (RMSE) or mean absolute error (MAE)? -Arguments against avoiding RMSE in the literature. Geoscientific model development, 7(3), pp.1247-1250. DOI:10.5194/gmd-7-1247-2014

Christensen, J.H., Carter, T.R., Rummukainen, M. and Amanatidis, G., 2007. Evaluating the performance and utility of regional climate models: the PRUDENCE project. DOI 10.1007/s10584-006-9211-6

Costa, M., Goldberger, A.L. and Peng, C.K., 2002. Multiscale entropy analysis of complex physiologic time series. Physical review letters, 89(6), p.068102. DOI: 10.1103/PhysRevLett.89.068102

Fordham, D. A., Wigley, T. M. L., \& Brook, B. W. (2011). Multi-model climate projections for biodiversity risk assessments. Ecological Applications, 21(8), 3317-3331. doi:10.1890/11-0314.1

Fowler, H. J., Blenkinsop, S., \& Tebaldi, C. (2007). Linking climate change modelling to impacts studies: recent advances in downscaling techniques for hydrological modelling. International Journal of Climatology, 27(12), 1547-1578. doi:10.1002/joc. 1556

Giorgi, F., Jones, C. and Asrar, G.R., 2009. Addressing climate information needs at the regional level: the CORDEX framework. World Meteorological Organization (WMO) Bulletin, 58(3), p.175.

Jacob, D., Elizalde, A., Haensler, A., Hagemann, S., Kumar, P., Podzun, R., Rechid, D., Remedio, A.R., Saeed, F., Sieck, K. and Teichmann, C., 2012. Assessing the transferability of the regional climate model REMO to different coordinated regional climate downscaling experiment (CORDEX) regions. Atmosphere, 3(1), pp.181-199. DOI:10.3390/atmos3010181.

Macadam, I., Pitman, A. J., Whetton, P. H., \& Abramowitz, G. (2010). Ranking climate models by performance using actual values and anomalies: Implications for climate change impact assessments. Geophysical Research Letters, 37(16), n/a-n/a. DOI:10.1029/2010gl043877

Mogith, A., Salah, M., Ibrahim, S.M. and Hafiez, R.A., 2013. GROUNDWATER POTENTIALS AND CHARACTERISTICS OF EL-MOGHRA AQUIFER IN THE VICINITY OF QATTARA DEPRESSION. Egyptian Journal of Desert Research, 63(1), pp.1-20. DOI: 10.21608/EJDR.2013.5821

Nigussie, Y., van der Werf, E., Zhu, X., Simane, B., \& van Ierland, E. C. (2018). Evaluation of Climate Change Adaptation Alternatives for Smallholder Farmers in the Upper Blue-Nile Basin. Ecological Economics, 151, $142-150$. doi:10.1016/j.ecolecon.2018.05.006

Nikulin, G., Jones, C., Giorgi, F., Asrar, G., Büchner, M., Cerezo-Mota, R., ... Sushama, L. (2012). Precipitation Climatology in an Ensemble of CORDEX-Africa Regional Climate Simulations. Journal of Climate, 25(18), 6057-6078. doi:10.1175/jcli-d11-00375.1

Ojha, R., Kumar, D. N., Sharma, A., \& Mehrotra, R. (2014). Assessing GCM Convergence for India Using the Variable Convergence Score. Journal of Hydrologic Engineering, 19(6), 1237-1246. doi:10.1061/(asce)he.1943-5584.0000888

Parrachino, I., Dinar, A. and Patrone, F., 2006. Cooperative game theory and its application to natural, environmental, and water resource issues: 3. application to water resources. The World Bank. Doi: 10.1596/1813-9450-4074

Perkins, S. E., Pitman, A. J., Holbrook, N. J., \& McAneney, J. (2007). Evaluation of the AR4 Climate Models' Simulated Daily Maximum Temperature, Minimum Temperature, and Precipitation over Australia Using Probability Density Functions. Journal of Climate, 20(17), 4356-4376. doi:10.1175/jcli4253.1 
Raju, K.S. and Kumar, D.N., 2014. Ranking of global climate models for India using multicriterion analysis. Climate Research, 60(2), pp.103-117. doi: 10.3354/cr01222

Raju, K.S. and Kumar, D.N., 2018.Impact of Climate Change on Water Resources with Modeling Techniques and Case Studies, Springer.

Sharifi, E., Steinacker, R., \& Saghafian, B. (2016). Assessment of GPM-IMERG and Other Precipitation Products against Gauge Data under Different Topographic and Climatic Conditions in Iran: Preliminary Results. Remote Sensing, 8(2), 135. doi: $10.3390 /$ rs 8020135

Srinivasa Raju, K., Sonali, P., \& Nagesh Kumar, D. (2016). Ranking of CMIP5-based global climate models for India using compromise programming. Theoretical and Applied Climatology, 128(3-4), 563-574. doi:10.1007/s00704-015-1721-6

Sunyer, M. A., Madsen, H., \& Ang, P. H. (2012). A comparison of different regional climate models and statistical downscaling methods for extreme rainfall estimation under climate change. Atmospheric Research, 103, 119-128. doi:10.1016/j.atmosres.2011.06.011

Wei, S., \& Leung, H. (2015). Compromise Rank Genetic Programming for Automated Nonlinear Design of Disaster Management. Mathematical Problems in Engineering, 2015, 1-14. doi:10.1155/2015/873794

Willmott, C., \& Matsuura, K. (2005). Advantages of the mean absolute error (MAE) over the root mean square error (RMSE) in assessing average model performance. Climate Research, 30, 79-82. doi:10.3354/cr030079

Xiao-Ge, X., Tong-Wen, W., \& Jie, Z. (2013). Introduction of CMIP5 Experiments Carried out with the Climate System Models of Beijing Climate Center. Advances in Climate Change Research, 4(1), 41-49. doi:10.3724/sp.j.1248.2013.041

Yin, J., Yuan, Z., Yan, D., Yang, Z. and Wang, Y., 2018. Addressing climate change impacts on streamflow in the Jinsha River basin based on CMIP5 climate models. Water, 10(7), p.910. doi:10.3390/w10070910 